The Egyptian Journal of Hospital Medicine (July 2021) Vol. 84, Page 1945-1954

\title{
Mental Health Outcomes Among Health Care Workers Exposed to Covid-19 Pandemic, Qalyoubia Governorate: Cross-Sectional Survey
}

\author{
Mai Abdullah Elmahdy*, Eman Mahmoud Shebl
}

Department of Public Health and Community Medicine, Faculty of Medicine, Benha University, Egypt

*Corresponding author: Mai Abdullah Elmahdy, Mobile: (+20) 01201882742, E-Mail: maielmahdy24@ yahoo.com

\begin{abstract}
Background: The pandemic caused by novel coronavirus disease 2019 (COVID-19) is considered the worst health crisis facing the entire world today. At the topmost of this crisis are the healthcare workers (HCWs) who are working to maintain well-being of all people. COVID-19 pandemic added more and more stress to healthcare workers in particular, depending on their work position. Objective: To assess mental health outcomes among HCWs dealing with confirmed or suspected COVID-19 patients. Methods: This is cross-sectional, hospital-based survey study conducted between Feb 6 and April 28, 2021. A total of 548 HCWs participated in the study. Mental health impact was assessed by using the 9item Patient Health Questionnaire (PHQ-9), the 7-item Generalized Anxiety Disorder (GAD-7) and the 7-item Insomnia Severity Index (ISI) questionnaires. Multivariable logistic regression analysis was done to determine the risk factors of mental health outcomes. Results: Among the $548 \mathrm{HCWs}$ surveyed; 64.8\% were nurses and 50.0\% aged from 26-30 years old. About 52.0\% worked in Benha University Hospital, 21.2\% worked in Toukh Fever Hospital, and 26.8\% worked in Qaha Central Hospital. A considerable proportion of HCWs had symptoms of anxiety, depression and insomnia. Nurses, workers aged from 26-30, those working in Qaha Central Hospital and those who had shift hours from 7-10 experienced more severe symptom levels of depression, anxiety, and insomnia. Nurses were associated with severe symptoms of anxiety, depression and insomnia.
\end{abstract}

Conclusion: The COVID-19 pandemic represents a new working challenge for HCWs and intervention strategies to prevent depression and anxiety to reduce the risk of adverse mental health outcomes are needed.

Keywords: Anxiety, COVID-19, Depression, (HCWs) Health Care Workers, Mental Health, Insomnia.

\section{INTRODUCTION}

The pandemic of the severe acute respiratory coronavirus 2 (SARS-COV-2) and its associated disease, named coronavirus disease 19 (COVID-19), was emerged at the end of December 2019 in Wuhan, China, then spread to the entire country, and then attracted large concern from around the world (1). As COVID-19 is rapidly spreading worldwide, on May 29, 2021, there have been 169,118,995 confirmed cases of COVID-19 worldwide, including 3,519,175 deaths. On $29^{\text {th }}$ of May 2021, Egypt reported 259,540 confirmed cases of COVID-19 and 14,950 deaths ${ }^{(2)}$. The situation in Egypt is becoming more and more critical and serious with the increasing number of cases and the large numbers of deaths caused by the disease ${ }^{(3,4)}$. Adding to this the governmental health expenditure in Egypt is only 5.3\% of gross domestic product (GDP), such limited resources combined with the continuous increasing number of cases place a huge burden on healthcare workers during the COVID-19 pandemic ${ }^{(5)}$.

Infectious disease outbreaks such as COVID-19 can cause depression, anxiety and emotional distress. These feelings of distress and anxiety can occur even in people that are not at high risk of getting sick $(6,7$, and 8$)$. Hence, facing this growing pandemic, HCWs especially the frontline who are directly involved in the diagnosis, treatment and care of COVID-19 patients were at risk of developing psychological stress and other mental health symptoms. The increasing number of suspected and confirmed cases, awesome workload, and reduction of personal protection equipment, extensive media coverage, lack of proper treatment or specific drugs, and feelings of being inadequately supported may all lead to the mental burden of healthcare workers ${ }^{(9)}$. Adding to all these previous factors, most health professionals working in quarantine units and hospitals very often do not receive any training for providing care of mental health ${ }^{(\mathbf{1 0})}$.

Furthermore, the mental health problems of HCWs would affect their clinical decision-making, attention and cognitive functioning, leading to a subsequent increase in the incidence of medical errors and medical problems, and thus putting patients at more risks ${ }^{(11,12)}$. It was also well known that acute stress in disasters can lead to a long-term effect on the overall health ${ }^{(13)}$. So, the mental health problems of HCWs during the COVID-19 pandemic became an important and crucial public health concern and addressing mental health issues of HCWs is important for improving pandemic prevention and control as well ${ }^{(\mathbf{1 4})}$.

This study aimed to assess mental health outcomes among Egyptian healthcare workers dealing with confirmed or suspected COVID-19 patients to be as an important indicator for the promotion of mental health

This article is an open access article distributed under the terms and conditions of the Creative Commons Attribution (CC BY-SA) license (http://creativecommons.org/licenses/by/4.0/) 
wellbeing among healthcare workers, by screening for symptoms of insomnia, anxiety and depression, and by analysing risk factors associated with those symptoms.

\section{PATIENTS AND METHODS}

\section{Study design, setting and participants:}

The study was a multi-center, cross-sectional, hospital-based study via a region-stratified, 2-stage cluster sampling conducted in Qalyoubia governorate, Egypt (from Feb 6 to April 28, 2021). Samples were stratified by their geographic location (ie, Qaha Center in which the main quarantine hospital in Qalyoubia governorate is located, Benha Center and Toukh Center). Hospitals equipped with fever clinics or wards for COVID-19 were eligible to participate in this survey. A total of three hospitals in Qalyoubia; Qaha central Quarantine hospital, Toukh Fever Hospital and Benha University Hospital, were included in the study.

Health workers included physicians and nurses of different departments in the selected hospitals were invited to participate in the study. Participants were divided into two groups; the first group, defined as "firstline workers", consisted of HCWs working in places with the highest probability of contact with COVID-19 cases, i.e., intensive care units, infectious diseases units, and emergency departments. The second group of "secondline workers" consisted of HCWs working in wards other than the intensive care unit, infectious diseases unit, and emergency department. Healthcare workers with history of any psychiatric disorder were excluded.

The target sample size of participants was calculated using PASS program version 15, setting the type-1 error $(\alpha)$ at 0.05 and margin of error $5 \%$. Result from previous study ${ }^{(15)}$ showed that $50.4 \%$ of healthcare workers dealing with COVID-19 cases had psychological co-morbidities (depression). Calculation according to these values produced a minimal sample size of 500 cases, taking in account $20 \%$ dropout rate, and using the formula; $N=\mathrm{Z} \alpha 2 \mathrm{P}(1-\mathrm{P}) / \mathrm{d} 2$, in which $\alpha=0.05$ and $\mathrm{Z} \alpha$ $=1.96$, and $\mathrm{d}=5 \%$. The final sample size of the study was 548.

\section{Ethical approval:}

Approval of the Research Ethics Committee of the Faculty of Medicine, Benha University was obtained. Informed consent was included in the survey explaining in details the study design and aim prior to respondents' enrollment. Participants could terminate the survey at any time they desired. The survey was anonymous, and confidentiality of information was assured.

\section{Main Outcomes and Measures}

Socio-demographic data of the participants including age (years), sex, educational level, marital status, place of work, name of department, work duration, numbers of shift hours and if shift hours increased during COVID-19 or not) were collected.

This study focused on symptoms of depression, anxiety and insomnia for all participants, using an interview questionnaire that includes:

1- The 7-item Generalized Anxiety Disorder (GAD-7) (16), Arabic version was used to identify patients with

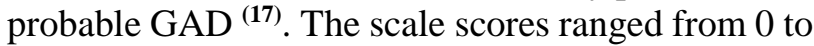
21 ; with scores of 0 to 4 were considered normal, scores of 5 to 9 indicated mild anxiety, scores of 10 to 14 indicated moderate anxiety, and scores of 15 to 21 were considered severe anxiety.

2- The 9-item Patient Health Questionnaire (PHQ-9) ${ }^{(17)}$, Arabic version was used ${ }^{(18)}$. The scale scores ranged from 0 to 27 ; scores of 0 to 4 were considered normal, 5 to 9 indicated mild depression, scores of 10 to 14 indicated moderate depression and scores of 15 to 21 were considered severe depression.

3- The 7-item Insomnia Severity Index (ISI) ${ }^{(19)}$, Arabic version was used ${ }^{(\mathbf{2 0})}$. The scale scores ranged from 0 to 28; with scores of 0 to 7 were considered normal, scores of 8 to 14 indicated subthreshold insomnia, scores of 15 to 21 indicated moderate insomnia while scores of 22 to 28 indicated severe insomnia.

\section{Data management and analysis}

Data were revised, coded, entered on a computer and analyzed using SPSS package version number 20. Quantitative data were tested for normality with ShapiroWilk test and described as mean and standard deviation (SD) or median/interquartile range according to data distribution. Independent $t$ test and one way ANOVA test were used to compare the severity of each symptom between two or more groups. Qualitative data were expressed as frequencies (n) and percentage (\%). Chisquare test was used to test the association between qualitative variables. Multivariate logistic regression analysis was performed for detection of risk factors for symptoms of anxiety, insomnia, depression, and stress in participants, after adjusting for confounders, including age, sex, marital status, job, educational level, type, and place of work, work duration and numbers of shift hours per day. P-value $\leq 0.05$ was considered significant.

\section{RESULTS}

In the study, among the 797 health care workers 285 [35.7\%] physicians and 512 [64.2\%] nurses were asked to participate, 548 respondents $(68.7 \%)$ completed the survey. Of the 548 responding participants, 193 (35.2\%) were physicians and $355(64.8 \%)$ were nurses. Of the participants, $285(52.0 \%)$ worked in Benha University Hospital, 116 (21.2\%) worked in Toukh Fever Hospital, and 147 (26.8\%) worked in Qaha Central Hospital. Most participants were women[355 (64.8\%)] 
aged from 26 to 30 years ,274 (50.0\%). Married, widowed, or divorced were 422 (77.0\%). Those who had an educational level of undergraduate were 212 (38.7\%) and those who had a percapita monthly income from 1000-2000 Egyptian pounds were 267 (48.7\%). HCWs who had less than five years of working duration were 227 (41.4\%) and who had shift hours from 7-10 hours were $240(43.8 \%)$. A total of 337 participants (61.5\%) were first-line health care workers directly engaged in diagnosing, treating, or caring for patients with or suspected to have COVID-19. More than half of participants [331 (60.4\%)] declared increase in shift hours during COVID-19 pandemic (table 1).

Table (1): Demographic and occupational characteristics of the studied group

\begin{tabular}{|c|c|c|c|}
\hline \multicolumn{2}{|l|}{ Characteristic } & \multirow{2}{*}{$\begin{array}{r}\mathrm{N}= \\
\mathbf{5 4 8} \\
49\end{array}$} & \multirow{2}{*}{$\begin{array}{c}\begin{array}{c}\% \\
(\mathbf{1 0 0 . 0})\end{array} \\
8.9\end{array}$} \\
\hline Age (years) & $18-25$ & & \\
\hline & $26-30$ & 274 & 50.0 \\
\hline & $31-40$ & 179 & 32.7 \\
\hline & $>40$ & 46 & 8.4 \\
\hline \multirow[t]{2}{*}{ Sex } & Male & 193 & 35.2 \\
\hline & Female & 355 & 64.8 \\
\hline \multirow[t]{3}{*}{ Education } & $\leq$ Secondary school & 207 & 37.8 \\
\hline & Undergraduate & 212 & 38.7 \\
\hline & Postgraduate & 129 & 23.5 \\
\hline \multirow[t]{2}{*}{ Occupation } & Physician & 193 & 35.2 \\
\hline & Nurse & 355 & 64.8 \\
\hline \multirow{2}{*}{$\begin{array}{l}\text { Marital } \\
\text { status }\end{array}$} & Married $^{* *}$ & 422 & 77.0 \\
\hline & Unmarried & 126 & 23.0 \\
\hline \multirow{3}{*}{$\begin{array}{l}\text { Percapita } \\
\text { monthly } \\
\text { income }(\mathrm{LE})^{*}\end{array}$} & $<1000$ & 123 & 22.4 \\
\hline & $1000-2000$ & 267 & 48.7 \\
\hline & $>2000$ & 158 & 28.9 \\
\hline \multirow[t]{3}{*}{ Work place } & $\begin{array}{l}\text { Benha University } \\
\text { hospital }\end{array}$ & 285 & 52.0 \\
\hline & Toukh Fever hospital & 116 & 21.2 \\
\hline & Qaha Central hospital & 147 & 26.8 \\
\hline \multirow{3}{*}{$\begin{array}{l}\text { Working } \\
\text { duration } \\
\text { (Years) }\end{array}$} & $<5$ & 227 & 41.4 \\
\hline & $5-10$ & 177 & 32.3 \\
\hline & $>10$ & 144 & 26.3 \\
\hline \multirow[t]{3}{*}{ Shift hours } & $4-6$ & 218 & 39.8 \\
\hline & $7-10$ & 240 & 43.8 \\
\hline & $>10$ & 90 & 16.4 \\
\hline \multirow{2}{*}{$\begin{array}{l}\text { Working } \\
\text { position }\end{array}$} & First line & 337 & 61.5 \\
\hline & Second line & 211 & 38.5 \\
\hline \multirow[b]{2}{*}{$\begin{array}{l}\text { Increased } \\
\text { shift hours } \\
\text { during } \\
\text { COVID-19 } \\
\text { pandemic }\end{array}$} & Yes & 331 & 60.4 \\
\hline & No & 217 & 39.6 \\
\hline
\end{tabular}

\section{Genealized Anxiety grade}

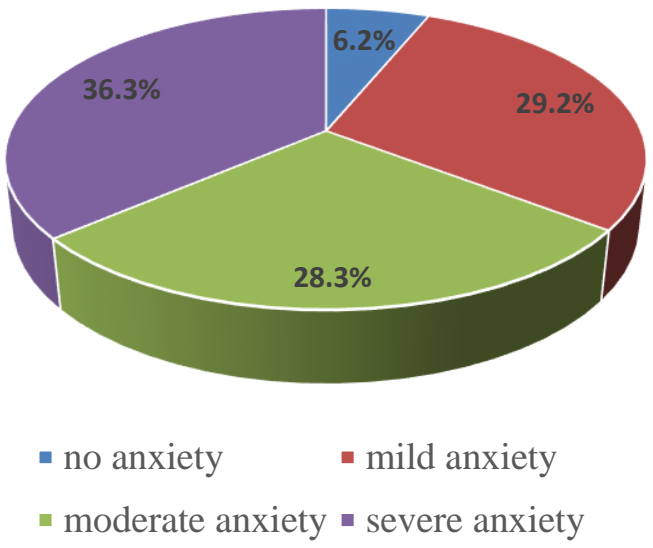

Figure 1 Generalized Anxiety Disorder grade among study participants $(n=548)$.

\section{Severity of Measurements and Associated Factors}

A considerable proportion of $\mathrm{HCWs}$ had symptoms of anxiety as 514 of the participants $(88.0 \%)$ were showing abnormal scores on the GAD-7 scale; 160 (29.2\%) were mild, 155 (28.3\%) were moderate, and 199 (36.3\%) were severe (Figure 1). According to the insomnia severity scale, $468(85.4 \%)$ showed positive results; 215 (39.2\%) were sub-threshold, 151 (27.6\%) were moderate and $102(18.6 \%)$ were severe. 548 (100.0\%) had depressive symptoms; $15(2.7 \%)$ were minimal, $90(16.4 \%)$ were mild, $150(27.4 \%)$ were moderate, 120 (21.9\%) were moderately severe and 173 $(31.6 \%)$ were severe (Figure 2).

Nurses, workers aged from 26-30 years, those working in Qaha Central Hospital and those who had shift hours from $7-10$ were experiencing more severe symptom levels of depression, anxiety, and insomnia (e.g. severe anxiety among physicians [53 (26.6\%)] vs nurses $[146(73.4 \%)](\mathrm{P}=0.002)$. Workers aged from 26 30 years declared more severe depression [93 (53.8\%) vs $10(5.8 \%)$ respectively; $\mathrm{P}<.001]$ and insomnia symptoms [64 (62.7) vs 3 (2.9\%) respectively; P <.001] compared to older ages. Among those working in Qaha Central Hospital compared to those working in Benha University Hospital and Toukh Fever Hospital: 114 (65.9\%) vs 32 $(18.5 \%)$ and $27(15.6 \%)$ respectively; $\mathrm{P}<.001$.

Severe insomnia among those who had 7-10 shift hours compared to workers who had more than 10 shift hours and from 4-6 hours: $62(60.8 \%)$ vs $39(38.2 \%)$ and $1(1.0 \%)$ respectively: $\mathrm{P}<.001$ (Table 2). Compared to second-line workers, participants working in first-line were more likely to report severe symptoms of depression [118 (68.2\%) vs $55(31.8 \%) ; \mathrm{P}=.004]$ and insomnia [60 $(58.8 \%)$ vs $24(41.2 \%) ; \mathrm{P}=.01]$, but not anxiety (Table 2). 
https://ejhm.journals.ekb.eg/

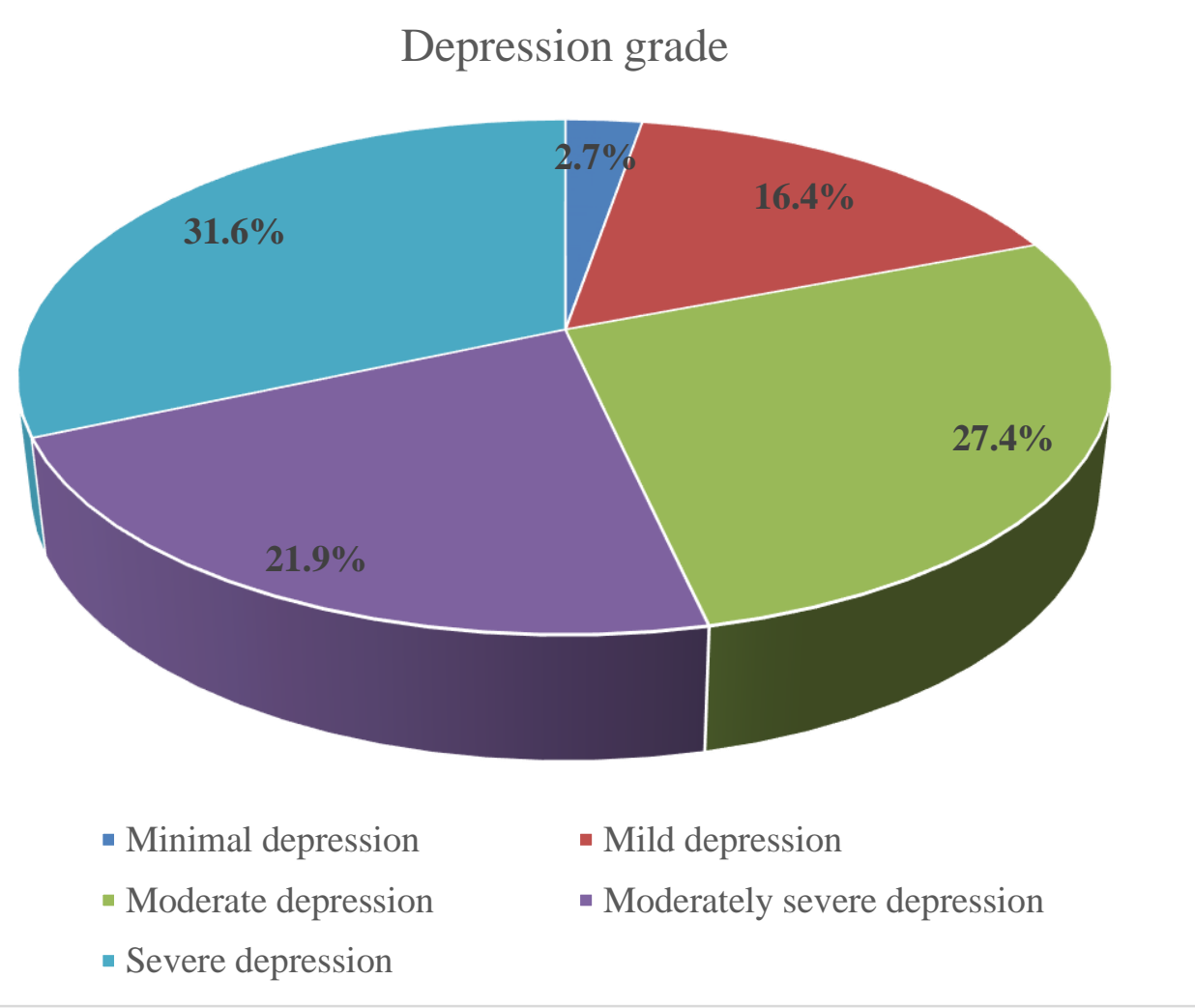

Figure 2 Depression grades among study participants $(\mathrm{n}=548)$. 
Table (2): Severity categories of Depression, anxiety and insomnia among the participants

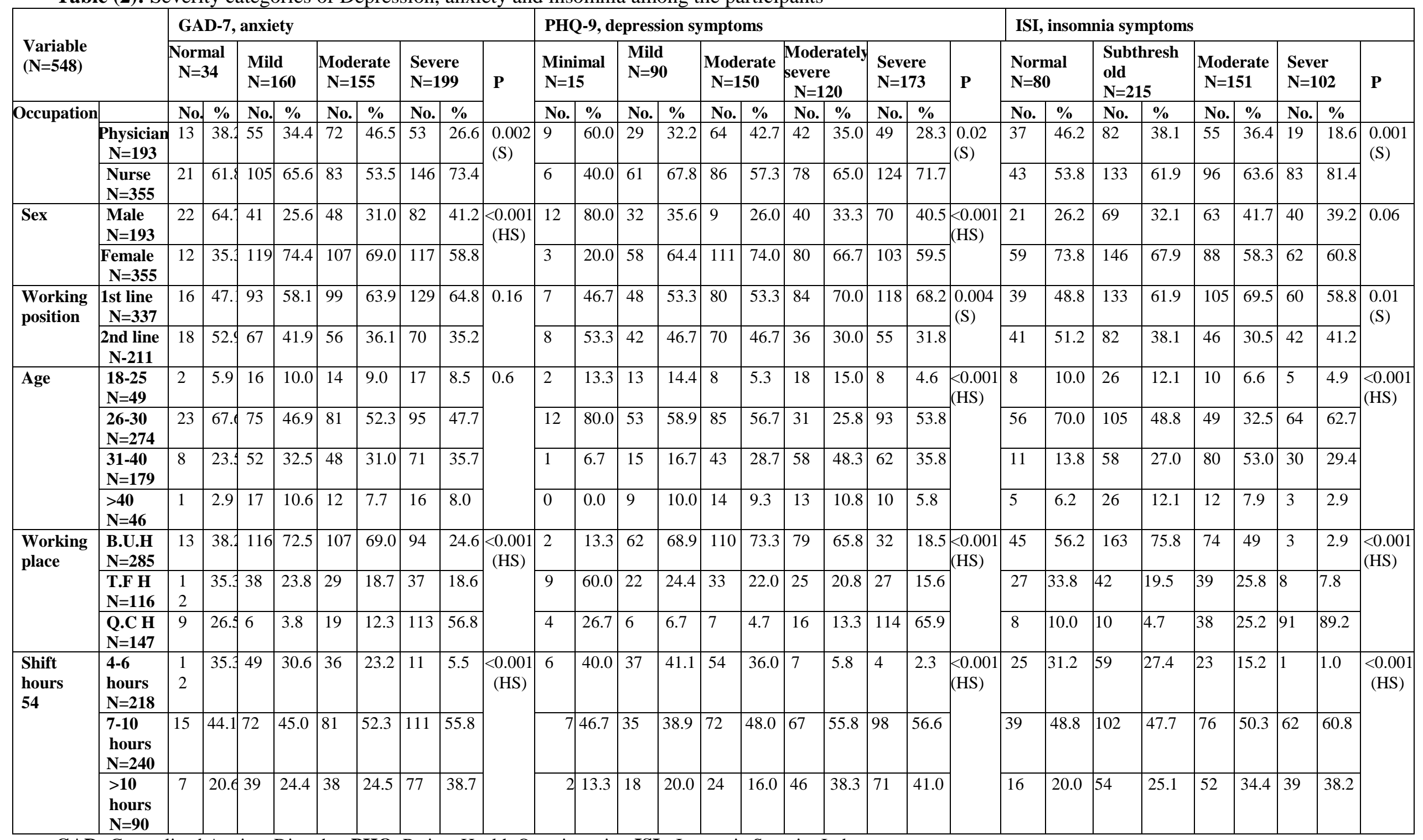

GAD: Generalized Anxiety Disorder, PHQ: Patient Health Questionnaire, ISI,: Insomnia Severity Index,

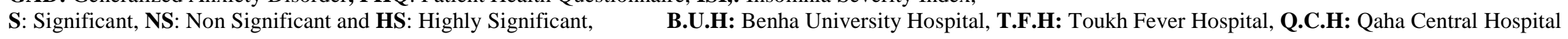


Table (3): Scores of Depression, Anxiety and Insomnia Measurements in the studied group

\begin{tabular}{|c|c|c|c|c|c|}
\hline $\begin{array}{l}\text { ISI, insomnia } \\
\text { symptoms }\end{array}$ & $\begin{array}{c}\text { PHQ-9, depression } \\
\text { symptoms }\end{array}$ & $\begin{array}{c}\text { GAD-7, anxiety } \\
\text { disorders }\end{array}$ & \multicolumn{3}{|c|}{$\begin{array}{c}\text { Scale } \\
(\mathrm{N}=548)\end{array}$} \\
\hline $15.01 \pm 7.12$ & $15.32 \pm 6.05$ & $11.96 \pm 5.07$ & Mean \pm SD & \multirow{2}{*}{\multicolumn{2}{|c|}{ Total score }} \\
\hline $14(1-28)$ & $15(0-27)$ & $12(0-21)$ & $\begin{array}{l}\text { Median } \\
\text { (Range) }\end{array}$ & & \\
\hline $13.82 \pm 6.39$ & $14.48 \pm 5.93$ & $11.56 \pm 5.09$ & Mean \pm SD & $\begin{array}{c}\text { Physician } \\
\mathrm{N}=193\end{array}$ & \multirow[t]{3}{*}{ Occupation } \\
\hline $15.66 \pm 7.42$ & $15.78 \pm 6.08$ & $12.18 \pm 5.06$ & Mean \pm SD & $\begin{array}{l}\text { Nurse } \\
\mathrm{N}=355\end{array}$ & \\
\hline $0.004(\mathrm{~S})$ & $0.01(\mathrm{~S})$ & 0.17 & \multicolumn{2}{|c|}{$\mathbf{P}$} & \\
\hline $16.15 \pm 6.79$ & $15.64 \pm 6.75$ & $12.18 \pm 5.46$ & Mean \pm SD & $\begin{array}{c}\text { Male } \\
\mathrm{N}=193\end{array}$ & \multirow[t]{2}{*}{ Sex } \\
\hline $14.39 \pm 7.23$ & $15.15 \pm 5.64$ & $11.84 \pm 4.85$ & Mean \pm SD & $\begin{array}{l}\text { Female } \\
\mathrm{N}=355\end{array}$ & \\
\hline 0.006 & 0.37 & 0.45 & \multicolumn{2}{|c|}{$\mathbf{P}$} & \multirow{4}{*}{ 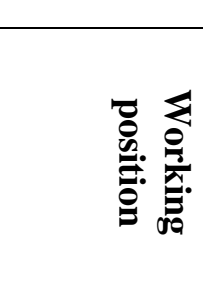 } \\
\hline $15.51 \pm 6.89$ & $15.97 \pm 5.93$ & $12.28 \pm 5.03$ & Mean \pm SD & $\begin{array}{c}\text { First-line } \\
\mathbf{N}=337\end{array}$ & \\
\hline $14.22 \pm 7.42$ & $14.28 \pm 6.12$ & $11.45 \pm 5.10$ & Mean \pm SD & $\begin{array}{l}\text { Second- } \\
\text { line } \\
\text { N-211 }\end{array}$ & \\
\hline $0.04(\mathrm{~S})$ & $0.001(\mathrm{~S})$ & 0.06 & \multicolumn{2}{|l|}{$\mathbf{P}$} & \\
\hline $11.94 \pm 4.80$ & $13.25 \pm 4.66$ & $10.46 \pm 4.03$ & Mean \pm SD & $\begin{array}{l}\text { B.U hosp } \\
\text { N }=285\end{array}$ & \multirow[t]{4}{*}{$\begin{array}{l}\text { Type of } \\
\text { hospital }\end{array}$} \\
\hline $13.31 \pm 6.04$ & $13.94 \pm 6.49$ & $11.33 \pm 6.18$ & Mean \pm SD & $\begin{array}{c}\text { T.F hosp } \\
\text { N= } 116\end{array}$ & \\
\hline $22.31 \pm 6.48$ & $20.43 \pm 5.07$ & $15.37 \pm 4.29$ & Mean \pm SD & $\begin{array}{l}\text { Q.C hosp } \\
\mathrm{N}=147\end{array}$ & \\
\hline$<0.001(\mathrm{HS})$ & $<0.001(\mathrm{HS})$ & $<0.001(\mathrm{HS})$ & \multicolumn{2}{|c|}{$\mathbf{p}$} & \\
\hline $10.95 \pm 4.94$ & $10.45 \pm 3.99$ & $9.05 \pm 4.22$ & Mean \pm SD & $\begin{array}{l}\text { 4-6 hours } \\
N=218\end{array}$ & \multirow[t]{4}{*}{ Shift hours } \\
\hline $15.59 \pm 7.35$ & $16.00 \pm 6.00$ & $12.43 \pm 4.95$ & Mean \pm SD & $\begin{array}{c}\text { 7-10 } \\
\text { hours } \\
\mathrm{N}=\mathbf{2 4 0}\end{array}$ & \\
\hline $16.73 \pm 6.97$ & $17.41 \pm 5.57$ & $13.10 \pm 5.11$ & Mean \pm SD & $\begin{array}{c}>10 \\
\text { hours } \\
\mathrm{N}=90\end{array}$ & \\
\hline$<0.001(\mathrm{HS})$ & $<0.001(\mathrm{HS})$ & $<0.001(\mathrm{HS})$ & & $\nabla$ & \\
\hline
\end{tabular}

GAD: Generalized Anxiety Disorder, PHQ: Patient Health Questionnaire, ISI,: Insomnia Severity Index, SD: Standard Deviation, S: Significant, NS: Non Significant and HS: Highly Significant, B.U.Hosp: Benha University Hospital, T.F.Hosp: Toukh Fever Hospital, Q.C.Hosp: Qaha Central Hospitl

\section{Scores of Measurements and Associated Factors:}

The mean $\pm \mathrm{SD}$ scores on the GAD-7 for anxiety, the PHQ-9 for depression and the ISI for insomnia, for all respondents were $11.96 \pm 5.07,15.32$ \pm 6.05 and $15.01 \pm 7.12$, respectively. Regarding GAD7 for anxiety score, those working in Qaha Central Hospital had significant higher scores compared to those who were working in Benha University or Toukh Fever Hospitals $(15.37 \pm 4.29$ vs $10.46 \pm 4.03$ and $11.33 \pm$ 6.18) respectively; $\mathrm{P}<.001$. While, participants had more than 10 shift hours had significant greater scores compared to workers had 4-6 or 7 to 10 shift hours $(13.10 \pm 5.11$ vs $9.05 \pm 4.22$ and $12.43 \pm 4.95)$ respectively; $\mathrm{P}<.001$ (Table 3 ).

Nurses, first-line health care workers, participants working in Qaha Central Hospital and workers had more than 10 shift hours had significant higher PHQ-9 and ISI scores compared to physicians, second-line health care workers. Those working in Benha University or Toukh Fever Hospitals and workers who had 4-6 or 7 to 10 shift hours respectively: nurses vs physician (PHQ-9 score; $15.78 \pm 6.08$ vs $14.48 \pm 5.93$, 
$\mathrm{P}=.01$ ), (ISI score; $15.66 \pm 7.42$ vs $13.82 \pm 6.39$, $\mathrm{P}=.004)$.

First-line vs second-line workers (PHQ-9 score; $15.97 \pm 5.93$ vs $14.28 \pm 6.12, \mathrm{P}=.001$, ISI score; 15.51 \pm 6.89 vs $14.22 \pm 7.42, \mathrm{P}=.04)$. Participants working in Qaha Central hospital vs those working in Benha University or Toukh Fever hospital (mean \pm SD PHQ-9 score; $20.43 \pm 5.07$ vs $13.25 \pm 4.66$ or $13.94 \pm 6.49$ respectively, $\mathrm{P}<.001$, mean \pm SD ISI score; $22.31 \pm$ 6.48 vs $11.94 \pm 4.80$ or $13.31 \pm 6.04$ respectively, $\mathrm{P}<$ $.001)$. Workers who had more than 10 shift hours vs workers who had 4-6 or 7 to 10 shift hours (PHQ-9 score; $17.41 \pm 5.57$ vs $10.45 \pm 3.99$ or $16.00 \pm 6.00$ respectively, $\mathrm{P}<.001$, ISI score; $16.73 \pm 6.97$ vs 10.95 \pm 4.94 or $15.59 \pm 7.35$ respectively, $\mathrm{P}<.001)($ Table 3 ).

\section{Risk Factors of Mental Health Outcomes:}

Multivariable logistic regression analysis showed that, after controlling for confounders, being a nurses and health care workers who had shift hours more than 10 hours were associated with severe symptoms of anxiety, depression and insomnia (e.g., severe anxiety among nurses: OR, 2.73; 95\% CI, 1.01-7.38; P = .04; severe depression among nurses: OR, 3.89; 95\% CI, $1.93-7.03 ; \mathrm{P}=.005$; sever insomnia among nurses: OR,
3.57; 95\% CI, 1.23 - 6.32; P <.01). While, severe anxiety among those working > 10 shift hours: OR, 3.03; 95\% CI, 1.65 -5.57; $\mathrm{P}<.001$. Severe depression among those working >10 shift hours: OR, 3.08; 95\% CI, 1.06 - 6.65; $\mathrm{P}<.001$. Sever insomnia among those working $>10$ shift hours; OR, 4.10; 95\% CI, 2.07-8.10; P <.001). Compared to workers in Benha University Hospital, workers in Qaha Central Hospital were associated with more severe symptoms of anxiety (OR, $1.85 ; 95 \% \mathrm{CI}$, $1.14-3.01 ; \mathrm{P}=.01)$ and insomnia $(\mathrm{OR}, 2.66 ; 95 \% \mathrm{CI}$, 1.26 - 7.60; $\mathrm{P}<.001)$.

Unmarried health care workers were associated with a lower risk of severe depression (OR, 0.22; 95\% CI, $0.08-0.93 ; \mathrm{P}=.03)$ and insomnia symptoms $(\mathrm{OR}$, $0.24 ; 95 \% \mathrm{CI}, 0.07-0.64 ; \mathrm{P}=.006)$ than married participants. Regarding age, study subjects aged $>40$ years old were significantly associated with more severe depression (OR, 3.27; 95\% CI, $1.09-9.83$; $\mathrm{P}=.03$ ). Age and income were significant independent risk factors for insomnia, where participants aged $>40$ years old (OR, $0.46 ; 95 \% \mathrm{CI}, 0.24-0.88 ; \mathrm{P}=.02$ ) and their monthly income > $2000 \mathrm{LE}(\mathrm{OR}, 0.45 ; 95 \% \mathrm{CI}, 0.24-0.85 ; \mathrm{P}=$ $.01)$ were associated with significant lower risk of sever insomnia (Table 4).

Table (4): Multivariable Logistic Regression Analysis of risk factors for Mental Health Outcomes

\begin{tabular}{|c|c|c|c|}
\hline $\begin{array}{l}\text { GAD7-anxiety symptoms } \\
\text { Variable }(\mathrm{N}=548)\end{array}$ & Adjusted OR* & CI & $\mathbf{P}$ \\
\hline Occupation (Physician) & 2.73 & $1.01-7.38$ & $0.04(\mathrm{~S})$ \\
\hline Shift hours (4-6 hours) & 3.03 & $1.65-5.57$ & $<0.001$ (HS) \\
\hline Sex (Male) & 2.57 & $1.11-5.93$ & $0.02(\mathrm{~S})$ \\
\hline Working place (BU Hospital) & 1.85 & $1.14-3.01$ & $0.01(\mathrm{~S})$ \\
\hline $\begin{array}{l}\text { PHQ9-depression symptoms } \\
\text { Variable }(\mathrm{N}=548)\end{array}$ & Adjusted OR* & CI & $\mathbf{P}$ \\
\hline Marital status (married) & 0.22 & $0.08-0.93$ & $0.03(\mathrm{~S})$ \\
\hline Sex (Male) & 2.94 & $1.56-5.83$ & $0.01(\mathrm{~S})$ \\
\hline Shift hours (4-6 hours) & 3.08 & $1.06-6.65$ & $<0.001$ (HS) \\
\hline Occupation (Physician) & 3.89 & $1.93-7.03$ & $0.005(\mathrm{~S})$ \\
\hline Age $(18-25$ years $)$ & 3.27 & $1.09-9.83$ & $0.03(\mathrm{~S})$ \\
\hline $\begin{array}{l}\text { ISI-insomnia symptoms } \\
\text { Variable }(\mathrm{N}=548)\end{array}$ & Adjusted OR* & CI & $\mathbf{P}$ \\
\hline Workplace (BU Hospital) & 2.66 & $1.26-7.60$ & $<0.001(\mathrm{HS})$ \\
\hline Shift hours (4-6 hours) & 4.10 & $2.07-8.10$ & $<0.001(\mathrm{HS})$ \\
\hline Age (18-25 years) & 0.46 & $0.24-0.88$ & $0.02(\mathrm{~S})$ \\
\hline Income $(<1000 \mathrm{LE})$ & 0.45 & $0.24-0.85$ & $0.01(\mathrm{~S})$ \\
\hline Marital status (married) & 0.24 & $0.07-0.64$ & $0.006(\mathrm{~S})$ \\
\hline Occupation (Physician) & 3.57 & $1.23-6.32$ & $0.01(\mathrm{~S})$ \\
\hline
\end{tabular}

* Adjusted for age, sex, marital status, job, educational level, type, and place of work, work duration and numbers of shift hours per day GAD: Generalized Anxiety Disorder, PHQ: Patient Health Questionnaire, ISI: Insomnia Severity Index, OR: Odds Ratio, CI: Confidence Interval, S: Significant and HS: Highly Significant,

B.U. Hospital: Benha University Hospital. 


\section{DISCUSSION}

The psychological response to an epidemic of infectious diseases posed by healthcare workers was complex and might be affected by different factors. Feeling of vulnerability or loss of control and concerns about one's health and possibility being, infection of colleagues, spread of virus to others, health of family, and others especially children and old aged group were considered sources of distress among HCWs. Other factors related to work were uncertainty of employment, lack of getting rest, financial worries, exposure to critical life events such as death, and being isolated for long periods. Moreover, supplies shortage and an increasing flow of suspected and actual cases of COVID-19 are increasing the pressures on healthcare workers concerns ${ }^{(\mathbf{2 1}, \mathbf{2 2})}$. Furthermore, the worries of this group were exacerbated by high transmission rate and uncertainties about mode of transmission of COVID-19. It was recognized that droplet transmission was the main route. However, COVID-19 was also found on the surfaces like toilets, doors, personal items as cell phones etc. Thereby, anxiety levels among HCWs were heightened by being extra alert about their behavior and staying safe (e.g. not to touch their faces after contacting with cases or their belongings) ${ }^{(23)}$.

This cross-sectional survey enrolled 548 participants and revealed a high prevalence of mental health symptoms among healthcare workers treating patients with COVID- 19 in Egypt. Overall, 88.0\%, $100.0 \%$ and $85.4 \%$ of all participants reported symptoms of, anxiety, depression and Insomnia, respectively. These findings are consistent with another studies conducted in Egypt; Aly et al. ${ }^{(24)}$ also revealed high prevalence of mental health problems; anxiety $(90.5 \%)$ and depression (94\%) respectively. In addition, The revealed prevalence rates in the current study of anxiety and depression were comparable to a study, that declared Overall, $77.3 \%, 69.5 \%$ and $79.3 \%$, of all participants reported symptoms of, anxiety, Insomnia and depression, respectively ${ }^{(25)}$. In contrast, these results were higher than ones reported in different studies by Lai et al. ${ }^{\left({ }^{(9)}\right.}$, Zhang et al. ${ }^{(26)}$, and Zhang et al. ${ }^{(27)}$, which may reflect the difficult situation facing Egyptian frontline healthcare workers. It could be related to limited number of Egyptian physicians and nurses as reported by the world bank to be 0.5 per 1,000 person for doctors and 1.9 per 1,000 for nurses, which is lower than most of European and Asian countries including china. Adding to that the presence of low number of hospital beds available (1.6 per 1,000 people) ${ }^{(5,28)}$. Placing a huge responsibility on physicians to choose the appropriate cases, which will be most benefited from admission?

On the other hand, females were associated with higher risk of experiencing severe depression, anxiety and insomnia, which may be due to the already reported gender difference for anxious and depressive symptoms (28). This finding is consistent with previous studies $\mathbf{( 9 , 2 6 \text { , }}$ and 27). This might be attributed to the higher amount of time spent by them in patient care than other health workers.

Our study results showed that nurses reported more severe symptoms on all scores. This is supported by a study conducted in China, where nurses experienced more severe symptom levels of depression, anxiety, insomnia, and distress (9). However, inconsistent finding is reported by El Kholy et al. ${ }^{(25)}$, who found that physicians and higher rates educational levels were more prone to depression. This could be related to the lower number of nurses participation compared to physicians in their study.

Ages from 26 to 30 were at higher rates of experiencing insomnia and severe depression. A possible explanation is that those age groups usually occupy the junior to intermediate level jobs, which require longer working hours and more duties. Our findings are consistent with Lai et al. ${ }^{(9)}$ who showed that junior positions are associated with greater risk of psychological problems. Also, El Kholy et al. (25) revealed that HCWs aged 26-30 reported more severe depression and anxiety symptoms.

A comparison between three different types of hospitals, which form the main bulk of hospitals involved in diagnosis and management of COVID-19 patients was done. Toukh Fever and Benha University Hospitals are responsible for diagnosis mainly while Quarantine Hospitals are responsible for treatment of confirmed cases. This study reported that working in Qaha Central Hospital was associated with higher rates of severe depression, anxiety and insomnia than Toukh Fever and Benha University Hospitals. This may be due to direct prolonged contact with all confirmed cases of COVID-19 in Qalyoubia governorate and contact with critical cases and increased number of deaths of COVID-19 patients in Quarantine Hospitals, which may be greater than those hospitals involved in contact with suspected cases and sending referrals for isolation of confirmed cases. In contrast, this finding was contradictory with a study of El Kholy et al. ${ }^{(25)}$, who reported that working in Fever Hospitals was associated with higher rates of severe depression than Quarantine hospitals. The possible explanation is smaller percentage of participants working in Fever Hospital compared to those working in Quarantine Hospitals in their study. Another reason may be different sample profile.

\section{LIMITATIONS}

The cross-sectional nature for this study did not allow follow up of either progression of the 
symptomatology or improvement of healthcare providers. Also, it might be expected that the pandemic situation may have long term outcome that will only appear in later stages, which this study design cannot detect. The lack of baseline statistics of the abovementioned symptomatology prior to the pandemic situation may raise the debate of how to assess the exact impact of the situation. Moreover, there might be respondent bias as the findings were self-reported by health workers and based on a subjective scale. Importantly, the tool used in the study should be taken into consideration while reporting mental health outcomes. Specific type of mental illness was not identified, which may or may not have affected the current symptoms of anxiety, depression and insomnia.

Strengths:

This study provides early evidence on the mental health status among health workers during the COVID-19 pandemic in Egypt, which should be of interest to policymakers, health facility managers and those involved in the response to COVID-19 or any future epidemic.

\section{CONCLUSION}

Nurses, female gender who were working in Qaha Central Isolation Hospital dealing with confirmed patients with COVID-19, were associated with high rates of symptoms of depression, anxiety and insomnia. Protecting health care workers is an important component of public health measures for addressing the COVID-19 epidemic. Special interventions to promote mental well-being in health care workers exposed to COVID-19 need to be immediately implemented, with female nurses, and frontline workers.

\section{RECOMMENDATIONS}

Targeted interventions are needed to enhance the psychological health of HCWs and reinforce the capacity of healthcare system during the pandemic. Adequate support should be ensured, appropriate education and training provided, in addition to guaranteeing adequate resources. Moreover, psychosocial needs should be monitored, and psychosocial services can be delivered via telemedicine. Acknowledgement: The authors would like to thank all healthcare workers that took time to fill in the survey.

Funding: The author(s) received no financial support for the research, authorship, and/or publication of this article.

\section{REFERENCES}

1. Zhu N, Zhang D, Wang W et al. (2020): A Novel Coronavirus from Patients with Pneumonia in China. N Engl J Med., 382: 727-733.

2. World Health Organization (2021): Corona virus disease 2019 (COVID-19) situation report. World Health Organization, 2021. Available: https://www.who.int/emergencies/diseases/novelcoronavirus-

2019?gclid=CjwKCAjwzMeFBhBwEiwAzwS8zG_Knh vRT9dHna4zPbyqMsDDpFXuezq LJgja_Y53H6uL7sZ3hR82BoC_A8QAvD_BwE. Accessed on May 52021

3. Hassany M, Abdel-Razek W, Asem $\mathrm{N}$ et al. (2020): Estimation of COVID-19 burden in Egypt. The Lancet Infectious Diseases, 20 (8): 896-897.

4. Tuite A, Ng V, Rees $\mathbf{E}$ et al. (2020): Estimation of the COVID-19 burden in Egypt through exported case detection. The Lancet Infectious Diseases, 20 (8): 894803.

5. The World Bank (2020): Current health expenditure (\% of GDP) - Egypt, Arab Rep. Data.worldbank. org., 2020. Retrieved June 4, 2020, from https://data. worldbank.org/

6. Montemurro $N$ (2020): The emotional impact of COVID-19: From medical staff to common people. Brain Behavior and Immunity, 87: 23-24.

7. Rajkumar R (2020): COVID-19 and mental health: A review of the existing literature. Asian Journal of Psychiatry, 52: 102066-72.

8. Centers for disease control and prevention (2020): COVID-19. https://www.cdc.gov/coronavirus/2019ncov/daily-life-coping/managing-stress-anxiety.html

9. Lai J, Ma S, Wang Y et al. (2020): Factors associated with mental health outcomes among health careworkers exposed to coronavirus disease 2019. JAMA Network Open, 3 (3): 203976-83.

10. Lima C, Carvalho P, Lima I et al. (2020): The emotional impact of Coronavirus 2019- nCoV (new Coronavirus disease). Psychiatry Research, 287: 11291522.

11. Panagioti M, Geraghty K, Johnson J et al. (2018): Association between physician burnout and patient safety, professionalism, and patient satisfaction: a systematic review and meta-analysis. JAMA internal medicine, 178: 1317-31.

12. LeBlanc $V$ (2009): The effects of acute stress on performance: implications for health professions education. Academic Medicine, 84: 25-33.

13. Mulfinger N, Sander A, Stuber F et al. (2019): ClusterRandomised trial evaluating a complex intervention to improve mental health and well-being of employees working in hospital - a protocol for the SEEGEN trial. BMC Public Health, 19: 1694-99.

14. Banerjee D (2020): The COVID-19 outbreak: crucial role the psychiatrists can play. Asian J Psychiatr., 50: 102014-19.

15. Chua S, Cheung V, Cheung $C$ et al. (2004): Psychological effects of the SARS outbreak in Hong Kong on high-risk health care workers. The Canadian Journal of Psychiatry, 49 (6): 391-393.

16. Spitzer R, Kroenke K, Williams J et al. (2006): A brief measure for assessing generalized anxiety disorder. Archieves of Internal Medicine, 166 (10): 1092- 1097.

17. Spitzer R, Kroenke K, Williams J (1999): Validation and utility of a self-report version of PRIME-MD: The PHQ primary care study. Primary care evaluation of mental disorders. Patient Health Questionnaire JAMA., 282 (18): 1737-1744. 
18. Sawaya H, Atoui $M$, Hamadeh A et al. (2016): Adaptation and initial validation of the patient health questionnaire - 9 (PHQ-9) and the generalized anxiety disorder - 7 questionnaire (GAD-7) in an arabic speaking Lebanese psychiatric outpatient sample. Psychiatry Research, 239: 245-252.

19. Morin C, Belleville G, Belanger L et al. (2011): The Insomnia Severity Index: Psychometric indicators to detect insomnia cases and evaluate treatment response. Sleep, 34 (5): 601-608.

20. Suleiman K, Yates B (2011): Translating the insomnia severity index into Arabic. Journal of Nursing Scholarship, 43 (1): 49-53.

21. SINAnews (2020): Beijing: In January, Hubei had more than 3,000 medical infections, and the Wuhan Health and Medical Committee reported 'None' for half a month. Retrieved March 6, 2020, from https://news.sina.com. $\mathrm{cn} / \mathrm{o} / 2020-03-06 /$ dociimxyqvz8395569.shtml. Chinese.

22. World Health Organization (2020): Geneva: Shortage of personal protective equipment endangering health workers worldwide. from https://www.who.int/newsroom/detail/03-03-2020-shortageprotectiveequipment-endangeringhealthworkersworldwide.
23. Han Q, Lin Q, Ni Z et al. (2020): Uncertainties about the transmission routes of 2019 novel coronavirus. Influenza and Other Respiratory Viruses, 14 (4): 470471.

24. Aly H, Nemr N, Kishk R et al. (2020): Stress, anxiety and depression among healthcare workers facing COVID-19 pandemic in Egypt: a cross-sectional onlinebased study. BMJ Open, 11: 45281-45285.

25. Elkholy H, Tawfik F, Ibrahim I et al. (2020): Mental health of frontline healthcare workers exposed to COVID-19 in Egypt: a call for action. https://journals. sagepub.com/doi/full/10.1177/0020764020960192

26. Zhang W, Wang $K$, Yin $L$ et al. (2020): Mental health and psychosocial problems of medical health workers during the COVID-19 epidemic in China. Psychotherapy and Psychosomatics, 89 (4): 242-250.

27. Zhang C, Yang L, Liu S et al. (2020): Survey of insomnia and related social psychological factors among medical staff involved in the 2019 novel coronavirus disease outbreak. Frontiers in Psychiatry, 11: 306.

28. Albert $P$ (2015): Why is depression more prevalent in women? Journal of Psychiatry \& Neuroscience, 40 (4): 219-221. 